\title{
Guidelines
}

European

Thyroid Journal
Eur Thyroid J 2018;7:55-66

DOI: $10.1159 / 000486957$
Received: December 11, 2017

Accepted after revision: January 16, 2018

Published online: February 14, 2018

\section{European Thyroid Association (ETA) Guidelines for the Management of Amiodarone-Associated Thyroid Dysfunction}

\author{
Luigi Bartalena ${ }^{a}$ Fausto Bogazzi $^{b}$ Luca Chiovato ${ }^{c}$ Alicja Hubalewska- \\ Dydejczyk $^{d}$ Thera P. Links ${ }^{e}$ Mark Vanderpump ${ }^{f}$ \\ ${ }^{a}$ Department of Medicine and Surgery, University of Insubria, Varese, Italy; ${ }^{b}$ Department of Clinical and \\ Experimental Medicine, University of Pisa, Pisa, Italy; ${ }^{C}$ Unit of Internal Medicine and Endocrinology, Istituti Clinici \\ Scientifici Maugeri and University of Pavia, Pavia, Italy; ${ }^{\mathrm{d}}$ Department of Endocrinology, Jagiellonian University \\ Medical College, Cracow, Poland; e Department of Endocrinology, University Medical Center Groningen, University

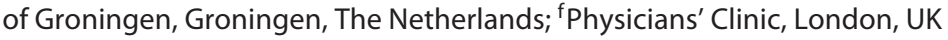

\section{Keywords}

Amiodarone $\cdot$ Amiodarone-induced hypothyroidism .

Amiodarone-induced thyrotoxicosis - Destructive

thyroiditis · Thionamides · Radioiodine - Thyroidectomy

\begin{abstract}
Treatment with amiodarone is associated with changes in thyroid function tests, but also with thyroid dysfunction (amiodarone-induced hypothyroidism, $\mathrm{AlH}$, and amiodarone-induced thyrotoxicosis, AIT). Both AIH and AIT may develop in apparently normal thyroid glands or in the presence of underlying thyroid abnormalities. AlH does not require amiodarone withdrawal, and is treated with levothyroxine replacement if overt, whereas subclinical forms may be followed without treatment. Two main types of AIT are recognized: type 1 AIT (AIT 1), a form of iodine-induced hyperthyroidism occurring in nodular goitres or latent Graves disease, and type 2 AIT (AIT 2), resulting from destructive thyroiditis in a normal thyroid gland. Mixed/indef-
\end{abstract}

inite forms exist due to both pathogenic mechanisms. AIT 1 is best treated with thionamides that may be combined for a few weeks with sodium perchlorate to make the thyroid gland more sensitive to thionamides. AIT 2 is treated with oral glucocorticoids. Once euthyroidism has been restored, AIT 2 patients are followed up without treatment, whereas AIT 1 patients should be treated with thyroidectomy or radioiodine. Mixed/indefinite forms of AIT are treated with thionamides. Oral glucocorticoids can be added from the beginning if a precise diagnosis is uncertain, or after a few weeks if response to thionamides alone is poor. The decision to continue or to stop amiodarone in AIT should be individualized in relation to cardiovascular risk stratification and taken jointly by specialist cardiologists and endocrinologists. In the presence of rapidly deteriorating cardiac conditions, emergency thyroidectomy may be required for all forms of AIT. (c) 2018 European Thyroid Association Published by S. Karger AG, Basel

\section{KARGER}

E-Mail karger@karger.com www.karger.com/etj (c) 2018 European Thyroid Association

Published by S. Karger AG, Basel
Prof. Luigi Bartalena

Department of Medicine and Surgery, University of Insubria

Endocrine Unit, ASST dei Sette Laghi

Viale Borri 57, IT-21100 Varese (Italy)

E-Mail luigi.bartalena@ uninsubria.it 


\section{Introduction}

Amiodarone is a benzofuranic, iodine-rich drug, especially effective in the management of supraventricular arrhythmias and usually given at a daily dose of $200 \mathrm{mg}$ [1]. Because of its high iodine content (about $37 \%$ by weight, with a daily dissociation rate of iodine from the drug of about 10\%) and pharmacological properties (inhibition of peripheral monodeiodination of thyroxine, $\mathrm{T}_{4}$ ), the drug causes changes in thyroid function tests and may be responsible for thyroid dysfunction. Approximately 15$20 \%$ of amiodarone-treated patients develop either thyrotoxicosis (amiodarone-induced thyrotoxicosis, AIT) or hypothyroidism (amiodarone-induced hypothyroidism, AIH) [2]. The type of thyroid dysfunction is in part dependent on iodine intake, since AIH is relatively more frequent in iodine-replete and AIT in iodine-deficient geographical areas [2]. Both AIT and AIH may occur early or late during amiodarone treatment, and develop in an apparently normal thyroid gland or in a gland with pre-existing abnormalities (nodular goitre, latent Graves disease, chronic autoimmune thyroiditis) [2]. The epidemiology of AIT has changed over a period of 25 years in Italy, as the prevalence of AIT due to destructive thyroiditis (see below) has progressively increased [1]; this might be related to iodine fortification, but evidence for this is lacking.

Diagnosis, classification, and management of amiodarone-induced thyroid dysfunction, particularly AIT, are often challenging, as reflected by the heterogeneous responses of expert thyroidologists to several recent surveys $[3,4]$. No specific predictors of the occurrence of amiodarone-associated thyroid dysfunction have been identified [5], although female gender and anti-thyroid peroxidase antibodies seem to predict AIH [6]. These uncertainties are related to the limited evidence in this field provided by randomized clinical trials. Therefore, in April 2017 the European Thyroid Association (ETA) commissioned a task force to provide practice guidelines for the management of amiodarone-associated thyroid dysfunction. A chairperson was selected to lead the task force (L.B.) and five additional ETA members were identified (F.B., L.C., A.H.-D., T.P.L., and M.V.) and subsequently approved by the ETA Guidelines Board and the ETA Executive Committee on the basis of their clinical expertise in this field. This document is aimed at reviewing current evidence and providing answers to questions commonly asked in daily clinical practice.

\section{Literature Search}

Data acquisition was based on PubMed search strategies, with particular regard to papers published in the last 30 years. Furthermore, the list of references of relevant citations and chapters of major textbooks were evaluated for any additional appropriate citation.

\section{Grading}

The GRADE system was used to make recommendations and express the quality of the evidence [7]. The task force used the following coding system: (1) indicates a strong recommendation and is associated with the phrase "we recommend;" (2) denotes a weak recommendation and is associated with the phrase "we suggest." Evidence grading: ØOOO denotes very low quality evidence; $\varnothing \varnothing О О$, low quality; ØØØ०, moderate quality; and $\varnothing \varnothing \varnothing \varnothing$, high quality. The draft was discussed by the members of the task force, and then posted on the ETA website for 4 weeks, inviting comments from ETA members.

\section{How Does Amiodarone Affect Thyroid Function Tests in Euthyroid Subjects?}

Most euthyroid patients started on amiodarone (usually $200 \mathrm{mg}$ /day) remain euthyroid, even if higher doses (400 mg/day) are used [8]. However, all amiodaronetreated patients undergo early ( $\leq 3$ months) and chronic ( $>3$ months) changes in serum thyroid function tests (Table 1). The huge iodine content of amiodarone increases plasma inorganic iodide 40 -fold and urinary iodide excretion up to $15,000 \mu \mathrm{g}$ per $24 \mathrm{~h}$. Due to the Wolff-Chaikoff effect, the thyroid adapts to iodine overload by inhibiting iodine organification and by reducing thyroid hormone production rate: the latter effect is the primary cause of the initial increase in serum thyrotropin (TSH) concentration. Short-term treatment with amiodarone $\left(400 \mathrm{mg} /\right.$ day for 3 weeks) decreased thyroxine $\left(\mathrm{T}_{4}\right)$ production rate and $\mathrm{T}_{4}$ metabolic clearance rate [8]. Amiodarone also inhibits the intracellular $\mathrm{T}_{4}$ transport and pituitary type 2 iodothyronine deiodinase (D2) activity, with a consequent reduction in intracellular triiodothyronine $\left(\mathrm{T}_{3}\right)$ generation and thyroid hormone binding to its cognate pituitary receptor [9]. However, these pituitary effects also occur in chronic stages during long-term amiodarone therapy and, therefore, are likely less important for the changes in TSH levels than the Wolff-Chaikoff effect. Later, the thyroid escapes from the WolffChaikoff effect [10], resulting in a normalization of $\mathrm{T}_{4}$ and TSH serum concentrations. In this phase, serum total 
Table 1. Changes in thyroid function tests occurring in euthyroid amiodarone-treated subjects

\begin{tabular}{|c|c|c|c|c|}
\hline Thyrotropin & Increased & $\begin{array}{l}\text { Decreased } \mathrm{T}_{4} \text { production } \\
\text { (Wolff-Chaikoff effect) } \\
\text { (major contribution) } \\
\text { Inhibition of pituitary D2 activity } \\
\text { (minor contribution) } \\
\text { Inhibition of T3 binding to its } \\
\text { pituitary receptor } \\
\text { (minor contribution) }\end{array}$ & Normal & $\begin{array}{l}\text { Normalized } \mathrm{T}_{4} \text { production } \\
\text { (escape from the } \\
\text { Wolff-Chaikoff effect) }\end{array}$ \\
\hline $\begin{array}{l}\text { Thyroxine }\left(\mathrm{T}_{4}\right) \text { : } \\
\text { total }\left(\mathrm{TT}_{4}\right) \text { and } \\
\text { free }\left(\mathrm{FT}_{4}\right)\end{array}$ & Increased & Inhibition of hepatic D1 activity & $\begin{array}{l}\text { Slightly increased/ } \\
\text { high normal }\end{array}$ & $\begin{array}{l}\text { Inhibition of hepatic } \mathrm{D} 1 \\
\text { activity } \\
\text { Increased } \mathrm{T}_{4} \text { production rate } \\
\text { Decreased } \mathrm{T}_{4} \text { metabolic } \\
\text { clearance rate }\end{array}$ \\
\hline Reverse $\mathrm{T}_{3}$ & Increased & Inhibition of hepatic D1 activity & Increased & $\begin{array}{l}\text { Inhibition of hepatic D1 } \\
\text { activity }\end{array}$ \\
\hline
\end{tabular}

D1, type 1 iodothyronine deiodinase; D2, type 2 iodothyronine deiodinase.

$\mathrm{T}_{4}\left(\mathrm{TT}_{4}\right)$, free $\mathrm{T}_{4}\left(\mathrm{FT}_{4}\right)$, and reverse $\mathrm{T}_{3}\left(\mathrm{rT}_{3}\right)$ levels increase, while serum total $\mathrm{T}_{3}\left(\mathrm{TT}_{3}\right)$ and free $\mathrm{T}_{3}\left(\mathrm{FT}_{3}\right)$ levels decrease because of the inhibitory effect of amiodarone on hepatic type 1 iodothyronine deiodinase (D1) activity $[11,12]$. The increase in serum $\mathrm{rT}_{3}$ concentration is usually far greater than the decrease in serum $\mathrm{T}_{3}$ concentration [13]. While amiodarone inhibits D1 activity in vivo, this effect has not been demonstrated in vitro for amiodarone but only for its metabolites [14]. The above changes in serum $\mathrm{T}_{4}, \mathrm{~T}_{3}$, and $\mathrm{rT}_{3}$ are observed early during amiodarone treatment and persist during prolonged treatment. After 3 months of therapy, a steady state is reached, with serum TSH returning to baseline values [14]. TSH normalization is likely related to an increase in $\mathrm{T}_{4}$ production rate and a reduction in $\mathrm{T} 4$ metabolic clearance rate $[8,15]$. Changes in $\mathrm{T}_{4}$ production and metabolic rates overcome the blockade of $\mathrm{T}_{3}$ generation, thus raising serum $\mathrm{T}_{3}$ levels into the low-normal range [15]. A trend towards lower serum TSH concentration has been observed with continued treatment and related to the cumulative dose of amiodarone $[2,15]$. Serum $\mathrm{TT}_{4}, \mathrm{FT}_{4}$, and $\mathrm{rT}_{3}$ levels remain at the upper end of normal range or are slightly elevated, whereas serum $\mathrm{T}_{3}$ (the biologically ac-

Management of Amiodarone-Associated Thyroid Dysfunction tive hormone) levels are in the low-normal range. Thus, with this biochemical profile amiodarone-treated patients are considered to be euthyroid.

\section{Should All Patients with AlH Be Treated and Should Amiodarone Be Withdrawn in These Patients?}

The prevalence of AIH may be as high as 26 and $5 \%$ of amiodarone-treated patients in its subclinical (serum TSH levels between upper reference value and $10 \mathrm{mU} / \mathrm{L}$, normal $\mathrm{FT}_{4}$ levels) and overt (serum TSH $>10 \mathrm{mU} / \mathrm{L}$, low $\mathrm{FT}_{4}$ levels) forms, respectively [16]. Although $\mathrm{AIH}$ may occur in patients with an apparently normal thyroid gland and absent thyroid autoimmunity, most frequently it develops in patients with underlying chronic autoimmune thyroiditis, with a higher prevalence in women and in those in iodine-replete areas $[2,17,18]$. There is no clear association between the daily or cumulative doses of amiodarone and the occurrence of AIH $[18,19]$. Clinical AIH symptoms do not differ from those of hypothyroidism of other origin, but it is worth mentioning that severe hypothyroidism may predispose to an increase in ventricular 


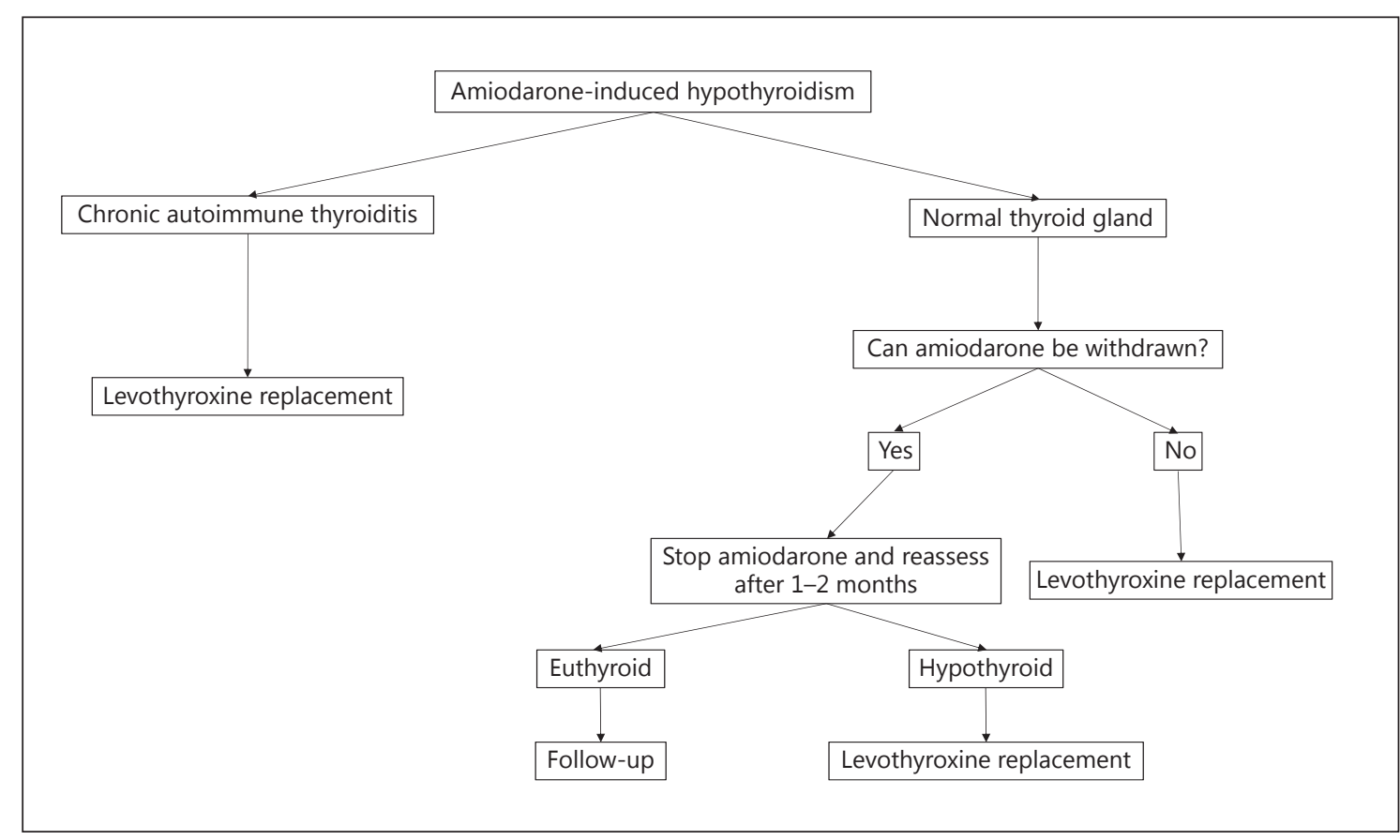

Fig. 1. Algorithm for the management of amiodarone-induced hypothyroidism.

susceptibility to life-threatening arrhythmias (e.g., torsade de pointes). Acute renal failure, reversible after levothyroxine $\left(\mathrm{L}-\mathrm{T}_{4}\right)$ replacement and amiodarone withdrawal, has been reported in one study [20]. Overt AIH is diagnosed biochemically on low serum $\mathrm{FT}_{4}$ and high serum TSH levels; $\mathrm{T}_{3}$ or $\mathrm{FT}_{3}$ are low even in euthyroid patients.

$\mathrm{AIH}$ is easily treated with $\mathrm{L}-\mathrm{T}_{4}$, and there is no need to discontinue amiodarone, if considered essential for the underlying cardiac disease [19]. Treatment of subclinical hypothyroidism may be unnecessary in some cases, particularly in the elderly, in view of the potential increase in risk of cardiovascular events [21]. Thyroid function should be tested every 4-6 months as there is a risk of progression to overt hypothyroidism [19], although subclinical AIH does not necessarily progress to overt $\mathrm{AIH}$ [20]. In AIH patients treated with $\mathrm{L}_{-} \mathrm{T}_{4}$, it is recommended that the $\mathrm{L}-\mathrm{T}_{4}$ dose be adjusted to normalize serum $\mathrm{FT}_{4}$ and $\mathrm{FT}_{3}$ levels and maintain serum TSH levels between the upper limit of the reference range or slightly below (upper third of normal range), and slightly elevated $(<10$ $\mathrm{mU} / \mathrm{L}$ ) values in the case of overt $\mathrm{AIH}$, to avoid the risk of overtreatment. If amiodarone is withdrawn, $\mathrm{L}-\mathrm{T}_{4}$ overtreatment should be avoided because of possible exacerbation of heart disease symptoms; in some cases the L- $\mathrm{T}_{4}$ dose needs to be reduced, and in others $\mathrm{L}_{-} \mathrm{T}_{4}$ may be discontinued, because AIH subsides in about $50 \%$ of cases within 2-3 months, particularly in the absence of underlying thyroid abnormalities [22]. Evidence is limited regarding the management of AIH in pregnancy [23]. Amiodarone is prescribed to pregnant women only when there are no alternatives and when the benefits outweigh the risks. It is reasonable to treat $\mathrm{AIH}$ as well as all other forms of hypothyroidism in pregnancy [23]. A therapeutic algorithm for AIH is shown in Figure 1.

Recommendation 1. AIH does not require amiodarone withdrawal. $\mathrm{L}-\mathrm{T}_{4}$ treatment is recommended in all cases of overt AIH, whereas it may be avoided in some subclinical cases, particularly in the elderly, but with a frequent assessment of thyroid status to monitor possible progression to overt hypothyroidism $(1, \varnothing \varnothing \bigcirc)$.

\section{How Many Types of AIT Can Be Identified and What Are the Diagnostic Criteria?}

Type 1 AIT (AIT 1) is a form of iodine-induced hyperthyroidism caused by excessive, uncontrolled biosynthesis of thyroid hormone by autonomously functioning thyroid tissue in response to iodine load, which typically develops in underlying nodular goitre or latent Graves disease $[1,2,24]$. Type 2 AIT (AIT 2) is a destructive thyroiditis occurring in an otherwise substantially normal
Bartalena/Bogazzi/Chiovato/HubalewskaDydejczyk/Links/Vanderpump 
Table 2. Common features of the two main forms of amiodarone-induced thyrotoxicosis (AIT 1 and AIT 2)

\begin{tabular}{lll}
\hline & AIT 1 & AIT 2 \\
\hline Underlying thyroid abnormalities & Yes & Usually no $^{\text {a }}$ \\
Colour-flow Doppler sonography & Increased vascularity & Absent hypervascularity $^{\text {Thy }}$ \\
Thyroidal RAIU & Low/normal/increased & Suppressed \\
Thyroid autoantibodies & Present if AIT is due to Graves disease & Usually absent \\
Onset time after starting amiodarone & Short (median 3 months) & Long (median 30 months) \\
Spontaneous remission & No & Possible \\
Subsequent hypothyroidism & No & Possible \\
First-line medical treatment & Antithyroid drugs ${ }^{\mathrm{d}}$ & Oral glucocorticoids \\
Subsequent definitive thyroid treatment & Generally yes & No \\
\hline
\end{tabular}

RAIU, radioiodine uptake. ${ }^{a}$ A small goitre may be present. ${ }^{b}$ In iodine-replete areas RAIU is always suppressed. ${ }^{c}$ Anti-thyroglobulin and anti-thyroid peroxidase antibodies do not allow a diagnosis of AIT $1 .{ }^{\mathrm{d}}$ Antithyroid drugs (thionamides) may be associated (for a few weeks) with sodium perchlorate.

thyroid gland $[1,2,24]$. A mixed/indefinite type is also recognized where patients acquire an overlapping condition of both types. AIT 2 is more prevalent in iodine-sufficient areas $[1,2,24]$ and, in general, is the most frequent form of AIT [25].

The diagnosis of AIT usually requires increased serum $\mathrm{FT}_{4}$ and $\mathrm{FT}_{3}$ and suppressed serum TSH levels. In rare cases of AIT associated with severe non-thyroidal illness, $\mathrm{FT}_{3}$ may be normal [26]. The absolute levels of $\mathrm{FT}_{4}$ and $\mathrm{FT}_{3}$ at presentation have no discriminatory value between AIT 1 and AIT 2, although they tend to be higher in AIT 2 [1]. Anti-thyroid antibodies, such as anti-thyroid peroxidase antibodies, are often positive in AIT 1 and negative in AIT 2 [1], although their presence does not necessarily allow a diagnosis of AIT 1 [27].

Nuclear medicine and ultrasound imaging have been utilized for differentiation of AIT 1, AIT 2, or mixed forms of the disease. The timing of imaging in the disease process matters. No imaging modality alone can accurately define the best treatment strategy which is at least partially due to the presence of mixed forms of the disease.

Three different tracers are available, including radioiodine (RAI) with ${ }^{131} \mathrm{I}$ or ${ }^{123} \mathrm{I},{ }^{99 \mathrm{~m}}$ pertechnetate $\left({ }^{99} \mathrm{mcO}^{-}\right)$ and ${ }^{99 \mathrm{~m}} \mathrm{TcO} 42$-methoxy-isobutyl-isonitrile (MIBI). In areas of baseline low/borderline low iodine intake, AIT 1 is accompanied by low, normal, or even high 24-h RAI uptake (RAIU), whereas the RAIU is mostly zero in patients with AIT 2. In iodine-replete environments, absent 24-h RAIU is invariably found in all patients taking amiodarone and it is not a useful investigation (Table 2) [1, 23]. Thus, RAIU has low diagnostic value in differentiat-

Management of Amiodarone-Associated

Thyroid Dysfunction ing AIT 1 from AIT 2 in iodine-replete areas. The sensitivity for AIT 1 and specificity for AIT 2 from the available, albeit limited, data in studies with ${ }^{99} \mathrm{TcO}^{-}$and MIBI scintigraphy is low as the patient numbers studied so far are small $[24,28,29]$. This particularly applies to areas with iodine sufficiency.

Thyroid ultrasonography can rapidly assess thyroid volume, nodularity, parenchymal echogenicity, and vascularity. Overall, most evidence shows that standard thyroid ultrasonography has low diagnostic value in AIT. Colour-flow Doppler sonography (CFDS) provides a non-invasive, real-time assessment of thyroid vascularity [24]. Although dependent on the necessary operator skills being available, it is, however, of great help in demonstrating the destructive nature of AIT 2 (absent hypervascularity in spite of high serum thyroid hormone levels) [1, 30] (Table 2).

The diagnosis of AIT 2 is based on the usual absence of goitre, reduced RAIU in areas of iodine deficiency, absence of hypervascularity on CFDS, and, in most cases, anti-thyroid antibody negativity (Table 2 ) $[1,2,24]$. AntiTSH receptor antibodies are absent.

\section{Is AIT Always an Emergency Situation?}

AIT can be a dangerous condition because it may exacerbate underlying cardiac abnormalities. AIT has been associated with increased morbidity and mortality, especially in older patients with impaired left ventricular function [31-33]. Thus, in the majority of cases, particularly in the elderly, prompt restoration and stable main- 
tenance of euthyroidism should be achieved as quickly as possible, and in selected categories of patients, detailed below, emergency management of AIT should be considered to obtain a prompt resolution of thyrotoxicosis.

From a general point of view, all patients with AIT should be considered potentially at risk of an emergency treatment. Thyrotoxicosis may be heralded, in some cases, by an unexplained increased sensitivity to warfarin due to an increased degradation of vitamin-dependent coagulation factors [34]. Thyrotoxicosis may precipitate cardiac dysfunction even in asymptomatic patients. This is unlikely in patients with subtle/minor cardiac abnormalities, but more frequent in those with severe heart disease (e.g., congenital or post-infarction heart disease or ventricular arrhythmias). Total thyroidectomy is, currently, the best option for a rapid restoration of euthyroidism in this subset of patients [35-37]. If total thyroidectomy is considered, a multidisciplinary evaluation of the AIT patient involving cardiologists, endocrinologists, surgeons, and anaesthesiologists is warranted to assess the risk-benefit balance in the individual patient. The choice of a specialist, high-volume thyroid surgeon is mandatory. Salvage thyroidectomy should be considered in the following conditions:

(a) patients with deterioration of cardiac function: patients with a reduced left ventricular ejection fraction (LVEF) have an increased mortality risk. AIT and left ventricular systolic dysfunction are independent factors associated with high cardiovascular morbidity and mortality [31,32]. In AIT patients with low LVEF, mortality may be as high as $30-50 \%[31,32]$. These findings suggest that in patients with severe underlying cardiac disease, prolonged exposure to high thyroid hormone levels may further deteriorate cardiac function and be responsible for the increased mortality rate [31,32]; and

(b) patients with a severe underlying cardiac disease (e.g., arrhythmogenic right ventricular dysplasia) or patients with malignant arrhythmias.

Surgery, by rapidly restoring euthyroidism, can improve cardiac function within 2 months, mainly in patients with severe left ventricular systolic dysfunction, thereby reducing the risk of mortality [35]. Plasmapheresis, aimed at removing the excess thyroid hormones from the circulation, has been reported to be efficacious in patients not responding to medical therapies, but this effect is usually transient and followed by an exacerbation of thyrotoxicosis. Thus, its real advantage is uncertain. However, plasmapheresis may be a helpful tool in preparing thyrotoxic patients prior to surgery [38].
Recommendation 2. We recommend that AIT patients should be considered at risk of an emergency treatment at any time due to the increased mortality and morbidity, particularly in the elderly and/or if a reduced left ventricular dysfunction is present $(1, \varnothing \varnothing \varnothing O)$.

Recommendation 3. We recommend that total thyroidectomy be performed without delay in AIT patients with deterioration of cardiac function or severe underlying cardiac disease and in those patients whose thyrotoxicosis is unresponsive to medical therapies. This decision should be made by a multidisciplinary team of specialist endocrinologist, cardiologist, anaesthesiologist, and high-volume thyroid surgeon $(1, \varnothing \varnothing \bigcirc)$.

\section{Can Amiodarone Be Continued in Some Cases of AIT?}

There is neither consensus nor sufficient evidence concerning the decision to either continue or stop amiodarone in AIT patients. This decision should be individualized with respect to risk stratification and taken jointly by specialist cardiologists and endocrinologists $[1,19]$. It is widely accepted that amiodarone should be continued in critically ill patients with life-threatening cardiac disorders responsive to the drug. Continuation of amiodarone treatment is probably also feasible in AIT 2 , as this form is often self-limiting. In a randomized clinical trial of 36 AIT 2 patients treated with methimazole plus prednisone or sodium perchlorate, or prednisone and sodium perchlorate, all patients reached euthyroidism in 8-14 weeks despite continuing amiodarone [39]. Similar results were reported in a small prospective study of 13 consecutive AIT 2 patients [40]. In a Japanese study of 50 AIT 2 patients who continued amiodarone, recurrent AIT 2 was observed in only 3 patients several years after the first episode of AIT [41]. On the other hand, in a large, matched retrospective cohort study of 83 AIT 2 patients, prednisone restored euthyroidism in most patients, irrespective of amiodarone continuation or withdrawal, but continuing amiodarone increased the recurrence rate of thyrotoxicosis, causing a delay in the stable restoration of euthyroidism and a longer heart exposure to thyroid hormone excess [42]. If cardiac conditions are stable and non-severe, amiodarone can be safely discontinued and, if needed, restarted after restoration of euthyroidism. The problem is more complex in AIT 1 and mixed/indeterminate AIT cases, and many endocrinologists favour amiodarone withdrawal, if feasible from the cardiological standpoint $[3,43]$. To summarize, the decision of whether amiodarone should be continued or withdrawn must take into account the potential benefit of ami- 


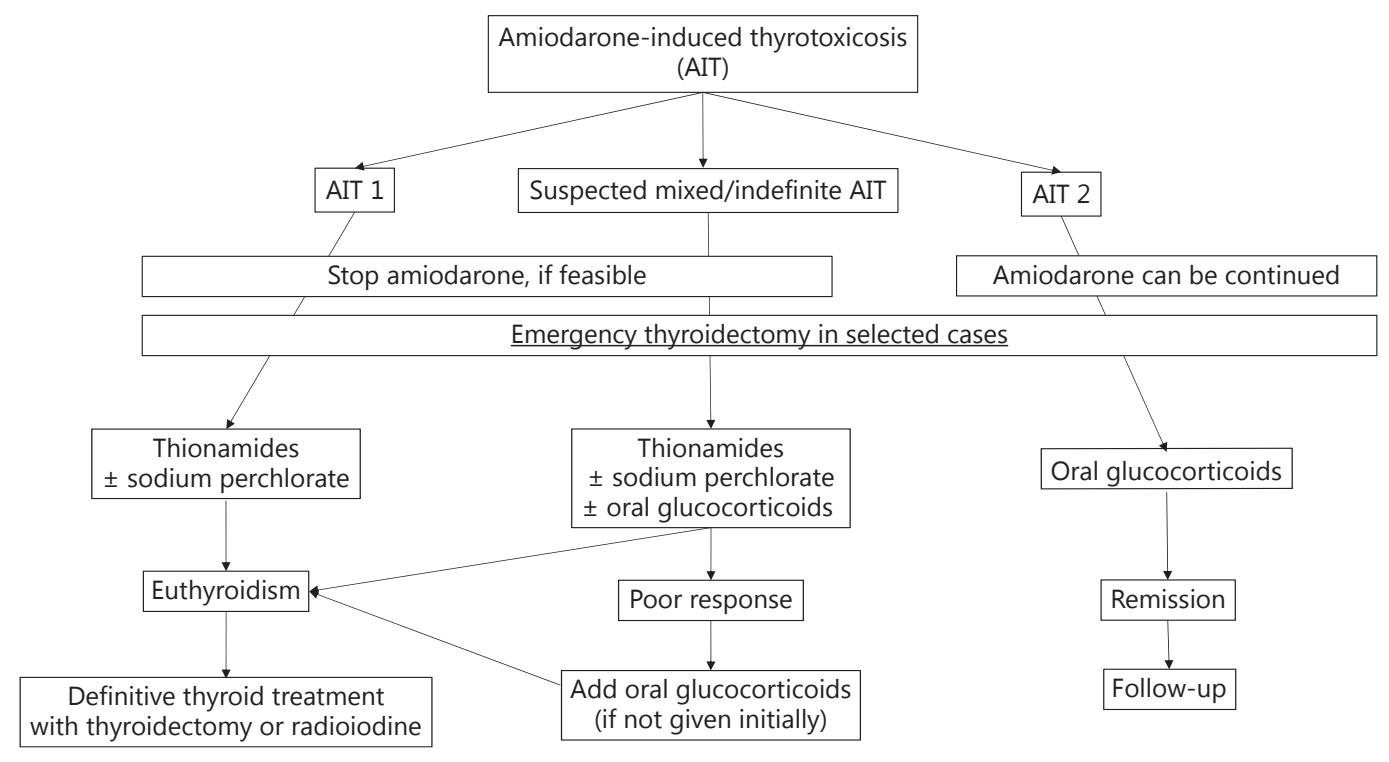

Fig. 2. Algorithm for the management of amiodarone-induced thyrotoxicosis (AIT). AIT 1, type 1 AIT; AIT 2 , type 2 AIT.

Table 3. Advantages and disadvantages of amiodarone withdrawal in patients with amiodarone-induced thyrotoxicosis (AIT)

\begin{tabular}{ll}
\hline Disadvantages & Advantages \\
\hline Efficient drug for life-threatening arrhythmias & $\begin{array}{l}\text { Amiodarone and its metabolites have a long half-life, making an } \\
\text { immediate exacerbation of cardiac symptoms unlikely }\end{array}$ \\
\hline $\begin{array}{l}\text { Cardiac protective properties: antagonistic effect on } \beta \text {-adrenergic } \\
\text { receptors, inhibition of } \mathrm{T}_{4} \text { deiodination, blockade of } \mathrm{T}_{3} \text { binding } \\
\text { to thyroid hormone receptors }\end{array}$ & $\begin{array}{l}\text { Greater chance of achieving euthyroidism and delivering } \\
\text { definitive thyroid treatment (particularly radioiodine) at an } \\
\text { earlier stage }\end{array}$ \\
$\begin{array}{l}\text { Amiodarone and its metabolites have a long half-life; thus, } \\
\text { discontinuation might be useless, at least in the short term }\end{array}$ & $\begin{array}{l}\text { Continuation of the drug in AIT 2 is associated with a delayed } \\
\text { restoration of euthyroidism and a higher chance of recurrence }\end{array}$ \\
\hline
\end{tabular}

odarone in life-threatening arrhythmias, the threat of a prolonged exposure to thyroid hormone excess, and the type of AIT (Table 3).

Recommendation 4. We suggest continuing amiodarone in life-threatening arrhythmias and in patients with critical illness with poor prognosis; in AIT 2 patients with non-life-threatening arrhythmias, the drug may be continued, but this may be associated with a prolongation of the period needed to achieve euthyroidism and, possibly, with a higher risk of recurrence. The decision to continue or to stop amiodarone should be individualized in relation to cardiovascular risk stratification and taken jointly by specialist cardiologists and endocrinologists (2, ØØОО).

\section{What Is the Management of AIT 1?}

Due to its prevalent pathogenic mechanism (see above), AIT 1 is best treated by antithyroid drugs (carbimazole, methimazole, or propylthiouracil) when a medical therapy is advisable (Fig. 2) [19, 44]. In some circumstances (see above) an emergency or salvage thyroidectomy may be the initial therapeutic choice.

The iodine-replete thyroid gland of AIT patients is less responsive to thionamides, so very high daily doses of the drug (40-60 mg/day of methimazole or equivalent doses of propylthiouracil) for longer than usual periods of time are often needed before euthyroidism is restored. This is 
obviously not an ideal situation in patients with underlying cardiac problems, whose hyperthyroidism should be promptly controlled. To increase the sensitivity and response of the thyroid gland to thionamides, potassium perchlorate, which decreases thyroid iodine uptake, has been used [2]. To minimize the adverse effects of the drug (particularly on the kidney and bone marrow), doses not exceeding $1 \mathrm{~g}$ /day were used. In addition, it is recommended not to use the drug for more than 4-6 weeks [2]. Because potassium perchlorate is no longer available, sodium perchlorate is an alternative option. Sodium perchlorate (Irenat ${ }^{\circledR}$ ) is available as a solution - 21 drops corresponding to about $300 \mathrm{mg}$ perchlorate. Thionamide therapy can be continued until euthyroidism is restored, if this is permitted by the underlying heart disease and cardiocirculatory compensation. After restoration of euthyroidism, a definitive therapy of the hyperfunctioning thyroid gland is usually advised (Fig. 2) [1]. This allows safe reintroduction or continuation of amiodarone, if needed from the cardiological standpoint. If amiodarone can be discontinued, RAI therapy can be performed when iodine contamination is over, which may be up to 6-12 months after cessation of amiodarone, as suggested by normalized iodine urinary excretion and adequate RAIU values. Otherwise, total thyroidectomy should be considered. Definitive treatment of AIT 1 with an underlying hyperfunctioning thyroid gland does not differ from that of spontaneous hyperthyroidism.

In AIT 1 treated with thionamides, data are not available on the time required to restore euthyroidism or factors that predict euthyroidism. In the absence of evidence suggesting the coexistence of destructive thyroiditis, the use of glucocorticoids in AIT 1 is not recommended.

Recommendation 5 . We recommend antithyroid drugs as the medical treatment of choice for most cases of AIT 1. Because the iodine-loaded thyroid gland is resistant to antithyroid drugs, a 4- to 6-week course of sodium perchlorate at doses not exceeding $1 \mathrm{~g} /$ day can be useful in accelerating control of hyperthyroidism $(1, \varnothing \varnothing \varnothing O)$.

\section{What Is the Management of AIT 2?}

Although AIT 2 is usually a self-limiting disease and may sometimes be mild, it can potentially exacerbate the underlying cardiac disease and, therefore, requires appropriate treatment [1]. The only randomized study available compared prednisone ( $30 \mathrm{mg} /$ day), sodium perchlorate (500 mg twice/day), or a combination of both drugs in 36 patients who continued amiodarone and were on methimazole $(30 \mathrm{mg} /$ day) from the onset of treatment [39]. Prednisone treatment resulted in euthyroidism in all patients, while $30 \%$ of the patients treated with sodium perchlorate alone needed additional prednisone treatment to become euthyroid [39]. Thus, prednisone was considered as the most effective treatment modality for these patients [39]. Although the study was underpowered, these data confirmed an earlier retrospective observation showing that a 6-week treatment of 42 AIT 2 patients with methimazole alone resulted in euthyroidism in $15 \%$ of patients compared to $76 \%$ of the patients treated with prednisone alone [45]. In a prospective randomized study of 12 patients, prednisone treatment alone was more effective in rapidly restoring euthyroidism compared to treatment with iopanoic acid [46]. An earlier study had proposed the use of lithium to normalize thyroid function in AIT patients, but the effectiveness is limited and has not been confirmed [47]. Thus, based on the available studies, oral glucocorticoids are the treatment of choice in AIT 2 (Fig. 2). The proposed initial dose is 30 $\mathrm{mg}$ /day of prednisone (or equivalent doses of other glucocorticoids) tapered down based on clinical and/or biochemical euthyroidism [48]. Severe cases of AIT 2 may require longer periods of treatment. If AIT presents an emergency (see paragraph above), salvage thyroidectomy can be considered in AIT 2, as well as in AIT 1 and mixed/ indefinite forms (Fig. 2).

Recommendation 6. We recommend oral glucocorticoids as the first-line treatment for AIT 2 with moderateto-severe thyrotoxicosis. The decision to treat milder or subclinical forms should be made taking into account the underlying cardiac conditions, with a close interaction with the specialist cardiologist $(1, \varnothing \varnothing \varnothing \mathrm{O})$.

Recommendation 7 . We suggest that in patients in whom AIT 2 presents as an emergency, salvage thyroidectomy can be considered as for AIT 1 and mixed/indefinite forms $(2, \varnothing \varnothing \bigcirc)$.

\section{What Is the Management of Mixed/Indefinite Forms of AIT?}

Distinguishing between AIT 1, AIT 2, or mixed/indefinite forms can be important to guide the subsequent management $[1,48]$. Mixed/indefinite forms of AIT, although not fully characterized, are encountered in clinical practice and are due to both pathogenic mechanisms of AIT 1 (iodine-induced hyperthyroidism) and AIT 2 (destructive thyroiditis) $[1,48]$. It is highly unlikely that AIT patients with a morphologically normal thyroid
62

Eur Thyroid J 2018;7:55-66 DOI: $10.1159 / 000486957$
Bartalena/Bogazzi/Chiovato/HubalewskaDydejczyk/Links/Vanderpump 
gland, absent vascularity, and negative tests for anti-TSH receptor antibodies have a mixed/indefinite form of AIT. In these patients, physical examination, a quick CFDS and anti-TSH receptor antibody measurement allow the diagnosis of AIT 2 and glucocorticoid treatment. The time required to achieve euthyroidism varies depending on thyroid volume and the severity of thyrotoxicosis at presentation [49].

The differentiation between AIT 1 and mixed/indefinite AIT is more difficult, often representing an exclusion diagnosis, especially in the presence of nodular goitres, and the therapeutic approach is uncertain. If a precise diagnosis cannot be made, two possible approaches can be proposed (Fig. 2). The first one is to start with thionamides ( \pm sodium perchlorate) as for AIT 1 and, in the absence of a biochemical improvement within a relatively short period of time (reasonably, 4-6 weeks), to add glucocorticoids with the assumption that a destructive component is also present superimposed on an underlying thyroid disorder. An alternative approach is represented by a combined treatment (thionamides and glucocorticoids) from the very beginning [50], which may expose a patient with cardiac disorders to undue glucocorticoid treatment. Evidence is lacking on the best therapeutic strategy for mixed/indefinite AIT, and randomized clinical trials are warranted. Because of the underlying thyroid disorder, a definitive treatment is usually required as for AIT 1. Thyroidectomy represents a valid option in the event of a poor response also to the combined treatment.

Recommendation 8. We suggest that in patients in whom a mixed/indefinite form of AIT is suspected, thionamides should be given initially. Whether glucocorticoids should be added from the very beginning or after a relatively short period (reasonably 4-6 weeks) of poor response remains to be established $(2, \varnothing \varnothing \mathrm{OO})$.

\section{What Is the Role of Thyroidectomy or RAI Treatment in the Management of AIT?}

In principle, RAI therapy is not feasible in the short term due to the iodine contamination and low RAIU values. RAI therapy with ${ }^{131} \mathrm{I}$ after stimulation with recombinant human TSH (rhTSH) alone or combined with lithium therapy has been proposed for the treatment of AIT patients to overcome the problem of low RAIU values [51]. However, owing to the very limited experience in this subset of patients and to the risk of an exacerbation of hyperthyroidism with consequent deleterious cardiac effects, this option should be considered with caution and is currently not recommended [52]. However, RAI therapy can be considered for the definitive therapy of the underlying hyperfunctioning thyroid gland in patients with AIT 1 after resolution of the iodine load and restoration of adequate RAIU values [1].

In addition to the emergency setting, total thyroidectomy can be considered in the following conditions [ 35 , $37,53,54]$ :

(a) as a definitive therapy of hyperthyroidism in alternative to RAI therapy;

(b) in patients who need to continue amiodarone therapy. In AIT 2 patients treated with glucocorticoids, continuation of amiodarone does not very much affect the time required for the first normalization of serum thyroid hormone levels. However, patients requiring continuation of amiodarone therapy show a high risk of recurrence of thyrotoxicosis during glucocorticoid therapy, although this information derives from a limited number of patients; accordingly, the surgical risk in this subset of patients should be carefully weighed against the possible (but not certain) risk of recurrent thyrotoxicosis. On the other hand, in AIT 1 patients, who need to continue amiodarone and have an underlying autonomously functioning thyroid gland, total thyroidectomy likely represents an appropriate option; and

(c) in patients showing adverse effect to medical therapy.

Recent studies have shown that total thyroidectomy can be performed in AIT patients, including those with moderate-to-severe left ventricular dysfunction, without serious complications $[35,37,53,54]$. Even though controlled studies are lacking, optimal preparation prior to surgery, including glucocorticoids and $\beta$-blockers, may reduce the surgical risk, irrespective of the AIT type. In general, restoration of euthyroidism before surgery is advisable, although controlled studies are not available. Plasmapheresis shortly before surgery may be considered.

Recommendation 9. We recommend ablation of a hyperfunctioning thyroid gland with an elective thyroidectomy or RAI treatment, as in other forms of spontaneous hyperthyroidism $(1, \varnothing \varnothing \varnothing \mathrm{O})$.

Recommendation 10 . We suggest that euthyroidism be restored before total thyroidectomy or RAI treatment, unless definitive treatment is urgent $(2, \varnothing \varnothing \mathrm{\varnothing O})$.

Recommendation 11. We recommend against the use of rhTSH stimulation prior to RAI therapy in patients with $\operatorname{AIT}(1, \varnothing 0 O O)$. 
Table 4. Summary of recommendations

\begin{tabular}{|c|c|c|}
\hline Number & Recommendation & $\begin{array}{l}\text { Strength of } \\
\text { recommendation } \\
\text { and level of evidence }\end{array}$ \\
\hline 1 & $\begin{array}{l}\text { Amiodarone-induced hypothyroidism }(\mathrm{AIH}) \text { does not require amiodarone withdrawal; } \\
\mathrm{L}-\mathrm{T}_{4} \text { treatment is recommended in all cases of overt } \mathrm{AIH} \text {, whereas treatment can be } \\
\text { avoided in some subclinical cases, particularly in the elderly, but with a frequent assessment of } \\
\text { thyroid status to monitor progression to overt hypothyroidism }\end{array}$ & $(1, \varnothing \varnothing \bigcirc О)$ \\
\hline 2 & $\begin{array}{l}\text { We recommend that amiodarone-induced thyrotoxicosis (AIT) patients should be considered at } \\
\text { risk of an emergency treatment at any time due to the increased mortality and morbidity, } \\
\text { particularly in the elderly and/or if a reduced left ventricular dysfunction is present }\end{array}$ & $(1, \varnothing \varnothing \varnothing \bigcirc)$ \\
\hline 3 & $\begin{array}{l}\text { We recommend total thyroidectomy to be performed without delay in AIT patients with } \\
\text { deterioration of cardiac function or severe underlying cardiac disease and in those patients whose } \\
\text { thyrotoxicosis is unresponsive to medical therapies; this decision should be made by a } \\
\text { multidisciplinary team of specialist endocrinologist, cardiologist, anaesthesiologist, and high- } \\
\text { volume thyroid surgeon }\end{array}$ & $(1, \varnothing \varnothing О О)$ \\
\hline 4 & $\begin{array}{l}\text { We suggest continuing amiodarone in life-threatening arrhythmias and in patients with critical } \\
\text { illness with poor prognosis; in AIT } 2 \text { patients with non-life-threatening arrhythmias, the drug may } \\
\text { be continued but this may be associated with a prolongation of the period needed to achieve } \\
\text { euthyroidism and, possibly, with a higher risk of recurrence; the decision to continue or to stop } \\
\text { amiodarone should be individualized in relation to cardiovascular risk stratification and taken } \\
\text { jointly by specialist cardiologists and endocrinologists }\end{array}$ & $(2, \varnothing \varnothing 00)$ \\
\hline 5 & $\begin{array}{l}\text { We recommend antithyroid drugs as the medical treatment of choice for most cases of AIT } 1 \text {; } \\
\text { because the iodine-loaded thyroid gland is resistant to antithyroid drugs, a } 4 \text { - to } 6 \text {-week course of } \\
\text { sodium perchlorate at doses not exceeding } 1 \mathrm{~g} / \text { day can be useful in accelerating control of } \\
\text { hyperthyroidism }\end{array}$ & $(1, \varnothing \varnothing \varnothing 0)$ \\
\hline 6 & $\begin{array}{l}\text { We recommend oral glucocorticoids as the first-line treatment for AIT } 2 \text { with moderate-to-severe } \\
\text { thyrotoxicosis; the decision to treat milder or subclinical forms should be made taking into account } \\
\text { the underlying cardiac conditions, with a close interaction with the specialist cardiologist }\end{array}$ & $(1, \varnothing \varnothing \varnothing \bigcirc)$ \\
\hline 7 & $\begin{array}{l}\text { We suggest that in patients in whom AIT } 2 \text { represents an emergency, salvage thyroidectomy can be } \\
\text { considered as for AIT } 1 \text { and mixed/indefinite forms }\end{array}$ & $(2, \varnothing \varnothing ం О)$ \\
\hline 8 & $\begin{array}{l}\text { We suggest that in patients in whom a mixed/indefinite form of AIT is suspected, thionamides } \\
\text { should be given initially; whether glucocorticoids should be added from the very beginning or after } \\
\text { a period of } 4-6 \text { weeks of poor response remains to be established }\end{array}$ & $(2, \varnothing \varnothing 00)$ \\
\hline 9 & $\begin{array}{l}\text { We recommend ablation of a hyperfunctioning thyroid gland with an elective thyroidectomy or } \\
\text { radioiodine (RAI) treatment, as in other forms of spontaneous hyperthyroidism }\end{array}$ & $(1, \varnothing \varnothing \varnothing \bigcirc)$ \\
\hline 10 & $\begin{array}{l}\text { We suggest that euthyroidism be restored before total thyroidectomy or RAI treatment, unless } \\
\text { definitive treatment is urgent }\end{array}$ & $(2, \varnothing \varnothing \mathrm{OO})$ \\
\hline 11 & $\begin{array}{l}\text { We recommend against the use of rhTSH stimulation prior to RAI therapy in } \\
\text { patients with AIT }\end{array}$ & $(1, \varnothing 000)$ \\
\hline
\end{tabular}

\section{Can Amiodarone Be Restarted (if Necessary) in Patients with Previous AIT?}

Only one study has addressed the issue of the reintroduction of amiodarone in patients with a history of AIT. In this retrospective study of 172 AIT patients, 46 needed a second course of amiodarone after a mean drug withdrawal of 2 years [55]. AIT recurred in 14 out of 46 patients (30\%), 12 out of 46 (26\%) developed $\mathrm{AIH}$, and the remaining 20 patients were euthyroid during a mean 6-year follow-up [55]. The majority of the patients who suffered from recurrent AIT (11 out of 14) were classified as having AIT 1 [55]. Other unpublished data, mentioned in Ryan et al. [56], reported a 9\% rate of either recurrent AIT or developing hypothyroidism after restarting amiodarone therapy. The question of whether preventive antithyroid drug treatment or ablative therapy should be given prior to the reintroduction of amiodarone is unanswered because of the lack of evidence. 


\section{Conclusions}

While AIH is easily managed, AIT represents a diagnostic and therapeutic challenge. Most patients with AIT 2 (destructive thyroiditis) are successfully treated by glucocorticoids and may not require amiodarone withdrawal. Treatment of AIT 1 (and mixed/indefinite forms) is far more complex because of resistance of the iodinereplete thyroid gland to antithyroid drugs. In view of the difficulties in the diagnostic differentiation between AIT 1 and mixed/indefinite forms, a multipharmacological approach is often used, and definitive treatment by RAI or thyroidectomy is generally necessary after its resolu- tion, sometimes during the thyrotoxic phase, especially in the presence of rapidly deteriorating cardiac conditions. As reflected by the recommendations summarized in Table 4, evidence in the field of amiodarone-associated thyroid dysfunction is very limited because controlled studies are scarce. Large, multicentre randomized clinical trials are warranted to improve the management of these disorders.

\section{Disclosure Statement}

The task force had no commercial support, and the members declare no conflict of interest.

\section{References}

1 Bogazzi F, Bartalena L, Martino E: Approach to the patient with amiodarone-induced thyrotoxicosis. J Clin Endocrinol Metab 2010;95: 2529-2535.

2 Martino E, Bartalena L, Bogazzi F, Braverman LE: The effects of amiodarone on the thyroid. Endocr Rev 2001;22:240-254.

3 Tanda ML, Piantanida E, Lai A, Liparulo L, Sassi L, Bogazzi F, Wiersinga WM, Braverman LE, Braverman LE, Martino E, Bartalena L: Diagnosis and management of amiodarone-induced thyrotoxicosis: similarities and differences between North American and European thyroidologists. Clin Endocrinol (Oxf) 2008;69:812-818.

4 Raghavan RP, Taylor PN, Bhake R, Vaidya B, Martino E, Bartalena L, Dayan CM, Bradley $\mathrm{K}$ : Amiodarone-induced thyrotoxicosis: an overview of UK management. Clin Endocrinol (Oxf) 2012;77:936-937.

5 Ahmed S, Van Gelder IC, Wiesfeld ACP, Van Veldhuisen DJ, Links TP: Determinants and outcome of amiodarone-associated thyroid dysfunction. Clin Endocrinol (Oxf) 2011;75: 388-394.

6 Trip MD, Wiersinga W, Plomp TA: Incidence, predictability, and pathogenesis of amiodarone-induced thyrotoxicosis and hypothyroidism. Am J Med 1991;91:507-511.

7 Swiglo BA, Murad MH, Schunemann HJ, Kunz R, Vigersky RA, Guyatt GH, Montori VM: A case for clarity, consistency and helpfulness: State-of-the-art clinical practice guidelines in endocrinology using the grading of recommendations, assessment, development, and evaluation system. J Clin Endocrinol Metab 2008;93:666-673.

8 Lambert MJ, Burger AG, Galeazzi RL, Engler $\mathrm{D}$ : Are selective increases in serum thyroxine $\left(\mathrm{T}_{4}\right)$ due to iodinated inhibitors of $\mathrm{T}_{4}$ monodeiodination indicative of hyperthyroidism? J Clin Endocrinol Metab 1982;55:1058-1065.
9 Nademanee K, Singh BN, Callahan B, Hendrickson JA, Hershman JM: Amiodarone, thyroid indexes, and altered thyroid function: long-term serial effects in patients with cardiac arrhythmias. Am J Cardiol1986;58:981986.

10 Franklyn JA, Davis JR, Gammage MD, Littler WA, Ramsden DB, Sheppard MC: Amiodarone and thyroid hormone action. Clin Endocrinol (Oxf)1985;22:257-264.

11 Yamazaki K, Mitsuhashi T, Yamada E, Yamada T, Kosaka S, Takano K, Obara T, Sato: Amiodarone reversibly decreases sodium-iodide symporter mRNA expression at therapeutic concentrations and induces antioxidant responses at supraphysiological concentrations in cultured human thyroid follicles. Thyroid 2007;17:1189-1200.

12 Melmed S, Nademanee K, Reed AW, Hendrickson JA, Singh BN, Hershman JM: Hyperthyroxinemia with bradycardia and normal thyrotropin secretion after chronic amiodarone administration. J Clin Endocrinol Metab 1981;53:997-1001.

13 Hershman JM, Nademanee K, Sugawara M, Pekary AE, Ross R, Singh BN, DiStefano JJ 3rd: Thyroxine and triiodothyronine kinetics in cardiac patients taking amiodarone. Acta Endocrinol (Copenh) 1986;111:193-199.

14 Amico JA, Richardson V, Alpert B, Klein I: Clinical and chemical assessment of thyroid function during therapy with amiodarone. Arch Intern Med 1984;144:487-490.

15 Unger J, Lambert M, Jonckheer MH, Denayer P: Amiodarone and the thyroid: pharmacological, toxic and therapeutic effects. J Intern Med 1993;233:435-443.

16 Wiersinga WM, Trip MD: Amiodarone and thyroid hormone metabolism. Postgrad Med J 1986;62:909-914.
17 Batcher EL, Tang XC, Singh BN, Singh SN, Reda DJ, Hershman JM; SAFE-T Investigators: Thyroid function abnormalities during amiodarone therapy for persistent atrial fibrillation. Am J Med 2007;120:880-885.

18 Zhong B, Wang Y, Zhang G, Wang Z: Environmental iodine content, female sex and age are associated with new-onset amiodaroneinduced hypothyroidism: a systematic review and meta-analysis of adverse reactions of amiodarone on the thyroid. Cardiology 2016; 134:366-371.

19 Bogazzi F, Tomisti L, Bartalena L, AghiniLombardi F, Martino E: Amiodarone and the thyroid: a 2012 update. J Endocrinol Invest 2012;35:340-348.

20 Harjai K, Licata A: Effects of Amiodarone on thyroid function. Ann Intern Med 1997;126: 63-73.

21 Stott DJ, Rodondi N, Kearney PM, Ford I, Westendorp RGJ, Mooijaart SP, Sattar N, Aubert CE, Aujesky D, Bauer DC, Baumgartner C, Blum MR, Browne JP, Byrne S, Collet TH, Dekkers OM, denElzen WPJ, DuPuy RS, Ellis G, Feller M, Floriani C, Hendry K, Hurley C, Jukema JW, Kean S, Kelly M, Krebs D, Langhorne P, McCarthy G, McCarthy V, McConnachie A, McDade M, Messow M, O’Flynn A, O’Riordan D, Poortvliet RKE, Quinn TJ, Russell A, Sinnott C, Smit JWA, Van Dorland HA, Walsh KA, Walsh EK, Watt T, Wilson R, Gussekloo J; TRUST Study Group: Thyroid hormone therapy for older adults with subclinical hypothyroidism. N Engl J Med 2017; 376:2534-2544.

22 Benjamens S, Dullaart RPF,Sluiter WJ, Rienstra M, van Gelder IC, Links TP: The clinical value of regular thyroid function tests during amiodarone treatment. Eur J Endocrinol 2017;177:9-14. 
23 Bartalena L, Bogazzi F, Braverman LE, Martino E: Effects of amiodarone administration during pregnancy on neonatal thyroid function and subsequent neurodevelopment. J Endocrinol Invest 2001;24:116-130.

24 Theodoraki A, Vanderpump MPJ: Thyrotoxicosis associated with the use of amiodarone: the utility of ultrasound in patient management. Clin Endocrinol (Oxf) 2016;84:172176.

25 Bogazzi F, Bartalena L, Dell'Unto E, Tomisti L, Rossi G, Pepe P, Tanda ML, Grasso L, Macchia E, Aghini-Lombardi F, Pinchera A, Martino E: Proportion of type 1 and type 2 amiodarone-induced thyrotoxicosis has changed over a 27-year period in Italy. Clin Endocrinol (Oxf) 2007;67:533-537.

26 Balzano S, Sau F, Bartalena L, Ruscazio M, Balestrieri A, Cherchi A, Martino E: Diagnosis of amiodarone-iodine-induced thyrotoxicosis (AIIT) associated with severe nonthyroidal illness. J Endocrinol Invest 1987;10: 589-591.

27 Tomisti L, Urbani C, Rossi G, Latrofa F, Sardella C, Manetti L, Lupi I, Marcocci C, Bartalena L, Curzio O, Martino E, Bogazzi F: The presence of anti-thyroglobulin (TgAb) and/or anti-thyroperoxidase antibodies (TPOAb) does not exclude the diagnosis of type 2 amiodarone-induced thyrotoxicosis. J Endocrinol Invest 2016;39:585-591.

28 Piga M, Cocco MC, Serra A, Boi F, Loy M, Mariotti S: The usefulness of ${ }^{99 \mathrm{~m}}$ Tc-sestaMIBI thyroid scan in the differential diagnosis and management of amiodarone-induced thyrotoxicosis. Eur J Endocrinol 2008;159:423429.

29 Pattison DA, Westcott J, Lichtenstein M, Toh HB, Gunawardana D, Better N, Forehan S, Sivaratnam D: Quantitative assessment of thyroid-to-background ratio improves the interobserver reliability of technetium-99m sestamibi thyroid scintigraphy for investigation of amiodarone-induced thyrotoxicosis. Nucl Med Commun 2015;36:356-362.

30 Loy M, Perra E, Melis A, Cianchetti ME, Piga M, Serra A, Pinna G, Mariotti S: Color-flow Doppler sonography in the differential diagnosis and management of amiodarone-induced thyrotoxicosis. Acta Radiol 2007;48: 628-634.

31 Yiu KH, Jim MH, Siu CW, Lee CH, Yuen M, Mok M, Shea YF, Fan K, Tse HF, Chow WH: Amiodarone-induced thyrotoxicosis is a predictor of adverse cardiovascular outcome. J Clin Endocrinol Metab 2009;94:109-114.

32 O'Sullivan AJ, Lewis M, Diamond T: Amiodarone-induced thyrotoxicosis: left ventricular dysfunction is associated with increased mortality. Eur J Endocrinol 2006;154:533-536.

33 Wang TJ, Evans JC, Benjamin EJ, Levy D, LeRoy EC, Vasan RS: Natural history of asymptomatic left ventricular systolic dysfunction in the community. Circulation 2003;108:977982.
34 Tomisti L, Del Re M, Bartalena L, Tanda ML, Pucci A, Pambianco M, Danesi R, Braverman LE, Martino E, Bogazzi F: Effects of amiodarone, thyroid hormones and CYP2C9 and VKORC1 polymorphisms on warfarin metabolism: a review of the literature. Endocr Pract 2013;19:1043-1049.

35 Tomisti L, Materazzi G, Bartalena L, Rossi G, Marchello A, Moretti M, De Napoli L, Mariotti R, Miccoli P, Martino E, Bogazzi F: Total thyroidectomy in patients with amiodaroneinduced thyrotoxicosis and severe left ventricular systolic dysfunction. J Clin Endocrinol Metab 2012;97:3515-3521.

36 Pierret C, Tourtier JP, Pons Y, Merat S, Duverger V, Perrier E: Total thyroidectomy for amiodarone-associated thyrotoxicosis: should surgery always be delayed for pre-operative medical preparation? J Laryngol Otol 2012;126:701-705.

37 Kaderli RM, Fahrner R, Christ ER, Stettler C, Fuhrer J, Martinelli M, Vogt A, Seiler CA: Total thyroidectomy for amiodarone-induced thyrotoxicosis in the hyperthyroid state. Exp Clin Endocrinol Diabetes 2016;124:45-48.

38 Zhu L, Zainudin SB, Kaushik M, Khor LY, Chng CL: Plasma exchange in the treatment of thyroid storm secondary to type II amiodarone-induced thyrotoxicosis. Endocrinol Diabetes Metab Case Rep 2016;2016:160039.

39 Eskes SA, Endert E, Fliers E, GerskusRB, Dullaart RP, Links TP, Wiersinga WM: Treatment of amiodarone-induced thyrotoxicosis type 2: a randomized clinical trial. J Clin Endocrinol Metab 2012;87:499-506.

40 Uzan L, Guignat L, Meune C, Mouly S, Weber S, Bertagna X, Bertherat J, Thomopoulos P, Duboc D: Continuation of amiodarone therapy despite type II amiodarone-induced thyrotoxicosis. Drug Saf 2006;29:231-236.

41 Sato K, Shiga T, Matsuda N, Onoda N, Takano $\mathrm{K}$, Hagiara N, Kasanuki H: Mild and short recurrence of type II amiodarone-induced thyrotoxicosis in three patients receiving amiodarone continuously for more than 10 years. Endocrine J 2006;53:531-538.

42 Bogazzi F, Bartalena L, Tomisti L, Rossi G, Brogioni S, Martino E: Continuation of amiodarone delays restoration of euthyroidism in patients with type 2 amiodarone-induced thyrotoxicosis treated with prednisone: a pilot study. J Clin Endocrinol Metab 2011;96: 3374-3380.

43 Eskes SA, Wiersinga WM: Amiodarone and thyroid. Best Pract Res Clin Endocrinol Metab 2009;23:735-751.

44 Jabrocka-Hybel A, Bednarczuk T, Bartalena L, Pach D, Ruchała M, Kamiński G, KosteckaMatyja M, Hubalewska-Dydejczyk A: Amiodarone and the thyroid. Endokrynol Pol 2015; 66:176-186.
45 Bogazzi F, Tomisti L, Rossi G, Dell'Unto E, Pepe P, Bartalena L, Martino E: Glucocorticoids are preferable to thionamides as firstline treatment for amiodarone-induced thyrotoxicosis due to destructive thyroiditis: a matched retrospective cohort study. J Clin Endocrinol Metab 2009;94:3757-3762.

46 Bogazzi F, Bartalena L, Cosci C, Brogioni S, Dell'Unto E, Grasso L, Aghini-Lombardi F, Rossi G, Pinchera A, Braverman LE, Martino E: Treatment of type II amiodarone-induced thyrotoxicosis by either iopanoic acid or glucocorticoids: a prospective, randomized study. J Clin Endocrinol Metab 2003;88: 1999-2002.

47 Dickstein G, Shechner C, Adawi F, Kaplan J, Baron E, Ish-Shalom S: Lithium treatment in amiodarone-induced thyrotoxicosis. Am J Med 1997;102:454-458.

48 Han TS, Williams GR, Vanderpump MPJ: Benzofuran derivatives and the thyroid. Clin Endocrinol (Oxf) 2009;70:2-13.

49 Bogazzi F, Bartalena L, Tomisti L, Rossi G, Tanda ML, Dell'Unto E, Aghini-Lombardi F, Martino E: Glucocorticoid response in amiodarone-induced thyrotoxicosis resulting from destructive thyroiditis is predicted by thyroid volume and serum free thyroid hormone concentrations. J Clin Endocrinol Metab 2007;92:556-562.

50 Vanderpump MPJ: Use of glucocorticoids in amiodarone-induced thyrotoxicosis. Nat Rev Endocrinol 2009;5:650-651.

51 Albino CC, Paz-Filho G, Graf H: Recombinant human TSH as an adjuvant to radioiodine for the treatment of type 1 amiodaroneinduced thyrotoxicosis (AIT). Clin Endocrinol (Oxf) 2009;70:810-811.

52 Bogazzi F, Tomisti L, Ceccarelli C, Martino E: Recombinant human TSH as an adjuvant to radioiodine for the treatment of type 1 amiodarone-induced thyrotoxicosis: a cautionary note. Clin Endocrinol (Oxf) 2010;72:133134

53 Houghton SG, Farley DR, Brennan MD, van Heerden JA, Thompson GB, Grant CS: Surgical management of amiodarone-associated thyrotoxicosis: Mayo Clinic experience. World J Surg 2004;28:1083-1087.

54 Gough J, Gough IR: Total thyroidectomy for amiodarone-associated thyrotoxicosis in patients with severe cardiac disease. World J Surg 2006;30:1957-1961.

55 Maqdasy S, Batisse-Lignier M, Auclair C, Desbiez F, Citron B, Thieblot P, Roche B, Lusson JR, Tauveron I: Amiodarone-induced thyrotoxicosis recurrence after amiodarone reintroduction. Am J Cardiol 2016;117:11121116.

56 Ryan LE, Braverman LE, Cooper DS, Ladenson PW, Kloos RT: Can amiodarone be restarted after amiodarone-induced thyrotoxicosis? Thyroid 2004;14:149-153. 